\title{
Why Don't We Do It in the Field: Vidalia onion Producer Perspective son Harvest, Sort, and Storage Technologies
}

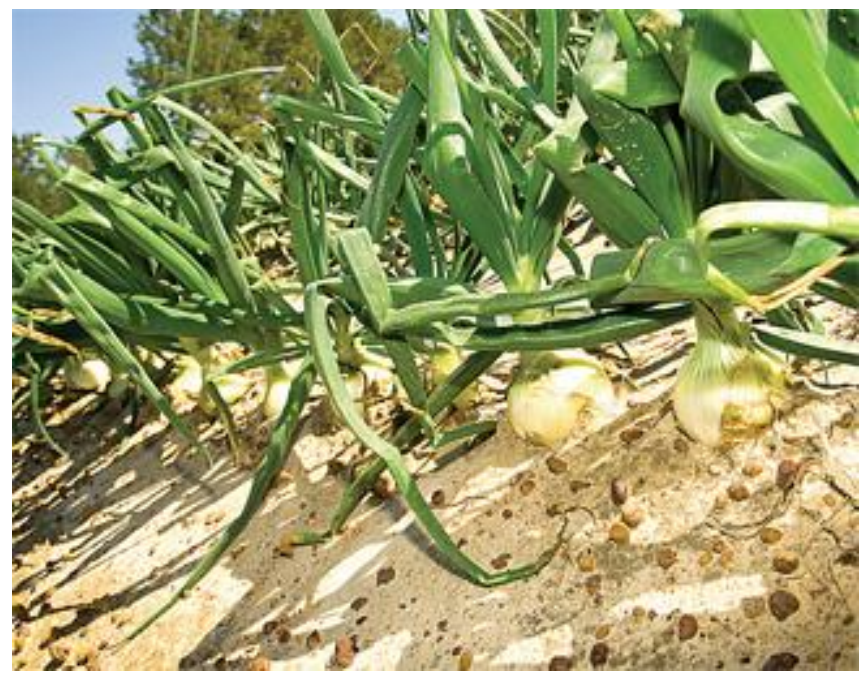

Joseph J. Molnar

\section{Lina Cui}

Department of Agricultural Economics and Rural Sociology

Auburn University

Auburn, Alabama, United States

\begin{abstract}
Onion (Allium cepa) is a major crop worldwide and one of the three largest and most highly valued fresh vegetable crops in the U.S. The rapid growth in demand for Vidalia onions, arguably America's preferred sweet onion, has been a remarkable success story of lucrative niche marketing of a value-added vegetable crop in the U.S. However, many post-harvest production challenges remain in the onion industry. Vidalia onions are prone to bruising and with more than 60 postharvest diseases, losses can reach up to 50\% annually. Through semistructured focused group interviews, industry members' perceptions on the needs for and possibilities of emerging postharvest technologies summarized. The long term goal of this project is to enhance onion postharvest handling efficiency and reduce storage losses via a comprehensive and multi-disciplinary research and extension effort integrating two major themes: (i) improve the efficiency and efficacy of onion quality inspection by integrating $x$-ray and hyper spectral imaging systems at the packing house; (ii) reduce storage losses by developing appropriate and innovative gas sensing and tracing technique. We provide a perspective on the social impact of the new technologies. The research should contribute to outreach and technology transfer efforts that support producer and processor decisions to install advance devices in their operations, that is, to ensure that the new technologies will truly benefit stakeholders. Current quality control is largely reliant on human visual inspection which fails to detect numerous internal onion defects; a looming labor shortage, increased global competition, and growing consumer expectations demands further improved and efficient technologies to perform this crucial step in quality control.
\end{abstract}

\section{Why Don't We Do It in the Field}

\section{Vidalia Onion Producer Perspectives on Harvest, Sort, and Storage Technologies}

\section{Introduction}

Sweet onions are one of the top five vegetable crops globally and are a significant dietary component in most culinary traditions. Sweet onions are usually preferred and command a premium price. 
The sweet onion industry faces increased competition, the need for improved varieties, and inadequate segregation of diseased onions prior to controlled atmosphere storage (Boyhan and Torrance, 2002). The crop brings in about $\$ 150$ million a year to legally registered growers in the 20 counties that make up the official Vidalia growing region. Storage losses are a major concern for growers. Controlled atmosphere storage losses can range from 10 to $20 \%$ in good years to as much as $50-70 \%$ in poor years. One main threat Botrytis neck rot (Botrytis allii). Considering that about $56.7 \mathrm{~kg}$ of onions can be placed in CA storage annually (University of Georgia College of Agricultural and Environmental Sciences, 2001), this fungal disease causes substantial economic losses for grower-packers (Mosquedo et al. 2010).

Onions, especially sweet onions, are perishable crops and are prone to bruises and postharvest diseases. Onions are susceptible to more than 60 diseases (Gabor,1996; Rabinowitch and Currah, 2002; Schwartz and Mohan, 2008). Consumers demand consistent and high quality products with uniform size, color and other external and internal quality attributes (Gunasekaran, 2001). Onions with both external and internal defects have a direct adverse effect on consumer satisfaction, market value, and profit for Vidalia onion growers and shippers (Shewfelt and Prussia, 1993). The internal defects such as internal decay, ring separation, and internal sprouting greatly reduce consumer satisfaction which is the key to the success in any specialty crop industry. Additionally, research results will be presented at regional and national level conferences diffusing the findings for further development by the fruit and vegetable industry at large.

The global produce industry is continually confronted by new technological challenges to meet the everincreasing consumer awareness and demand for quality-assured items. To face these challenges, one trend in agribusiness is declining reliance on subjective assessment of quality and increasing adoption of objective, quantitative and non-destructive techniques of quality assessment. Non-destructive instrument-based methods are preferred to destructive techniques because they allow the measurement and analysis of individual onions, reduce waste and permit repeated measures on the same item over time.

Machines for automatic quality sorting of agricultural products have been implemented in practice since the middle of the $20^{\text {th }}$ century. The improvement of the agricultural technologies and the food industry goes along with the remarkable development of the sorting technique: the range of products being non-destructively qualified using machines continually enlarges; the accuracy and the rate of qualification of the products increase; the design and the maintenance features are being modernized. In the structure of sorting machines, a computerized automatic classifier accomplishes the processing of information and control of decisions on each individual onion. Automatic classifiers are the central nervous system of sorting machines. The evolution of such machines and the software that controls them consists in the improving of the automatic classifier and quality of the onion that reaches the consumer.

Onion (Allium cepa) is a major crop worldwide and one of the three largest and most highly valued fresh vegetable crops in the U.S. Vidalia sweet onion is a significant specialty crop grown in the southeast area of Georgia, and comprises $15 \%$ of all onions consumed in the USA (NOA 2008). Vidalia onion was named Georgia's official state vegetable in 1990. It is famous due to its sweet flavor and high percentage of water, which is $98 \%$ compared to $60 \%$ of other type of onions. Because of its high water texture, this type of onion is easily bruised. Vidalia sweet onions owe their flavor to the absence of certain pungent compounds found in other varieties. The lack of these substances also makes them more susceptible to fungal or bacterial diseases (such as sour skin) compared to other onion varieties. Product quality and shelf life are key aspects of the Vidalia onion industry's program to protect the identity, reputation, and price premium accorded this food item.

A broad range of techniques ${ }^{1}$, have been employed for non-destructive testing of food quality in the onion (Li et al., 2009). Although conventional human visual inspection is still a dominant approach for ascertaining quality in most of onion packing houses, a number of machine vision-based inspection systems are employed for automatic sorting and grading of onions. These inspection systems, based on digital imaging techniques, are limited to external size or shape inspection but are unable to examine the internal quality of onion bulbs. Optical scanning cannot detect sour skin or other internal conditions. X-ray imaging has been reported to be the most promising method for detecting internal defects of Vidalia sweet onions, including voids and foreign inclusions (Mosqueda et al. 2010).

\footnotetext{
${ }^{1}$ Such as digital color camera imaging, near-infrared spectroscopy, mid-infrared spectroscopy, X-ray imaging, hyperspectral imaging, ultrasound and electronic nose 
New machinery has recently become available that seemingly makes a quantum leap forward in quality determination in the packing shed. Using x-ray imaging and carefully calibrated algorithms that classify onions on multiple dimension in real time, the onion bag a consumers purchases has a lower likelihood of misshapen, nonuniform, or early spoiling onions. The new instruments for sensing and measuring the quality attributes of fresh produce are costly and perhaps more complicated to repair. Among non-destructive quality assessment techniques, near-infrared spectroscopy (NIRS) is arguably the most advanced with regard to instrumentation, applications, accessories and chemometric software packages.

The rapid growth in demand for Vidalia onions, arguably America's preferred sweet onion, has been a remarkable success story of lucrative niche marketing of a value-added vegetable crop in the U.S. However, many postharvest production challenges remain in the onion industry. Vidalia onions are prone to bruising and with more than 60 postharvest diseases, losses can reach up to 50\% annually. Through semi-structured group interviews buttressed by individual interviews, industry members' perceptions on the needs for and possibilities of emerging postharvest technologies will be collected and analyzed. A quantitative socio-economic perspective will be constructed from published governmental and interview data to provide a contextual setting for observed perspectives and situations of the Vidalia onion industry.

The long term goal is to enhance onion postharvest handling efficiency and reduce storage losses via a comprehensive and multi-disciplinary research and extension effort integrating two major themes: (i) improve the efficiency and efficacy of onion quality inspection by integrating x-ray and hyper spectral imaging systems at the packing house; (ii) reduce storage losses by developing appropriate and innovative gas sensing and tracing technique. We will conduct a social impact assessment of these new technologies. We seek to contribute to outreach and technology transfer effort that ensure that the new technologies will truly benefit stakeholders. Current quality control is largely reliant on human visual inspection which fails to detect numerous internal onion defects; the looming labor shortage, increased global competition, and growing consumer expectations further demands improved and efficient technologies to perform this crucial step in quality control.

This project seeks to evaluate the social and economic impact of onion post-harvest technologies and engage in outreach and technology transfer. This research intends to guide the development of post-harvest technologies in order to create a commercial product that can be readily adopted, enabling the users to reap economic benefits facilitated by sorting machinery with enhanced defect detection capabilities. Information gathered from this project will also be used to formulate a perspective on technological change in this industry based on a variety of analytical tools. The analytic strategy utilizesthe results of group interviews that identify key areas of concern, information need, and priority in the Vidalia onion value chain (Fischer et al., 2006).

\section{Protecting Terroir}

Terroir, the concept that a local ecology and production practices bestow unique and distinctive qualities of an agricultural good, are foreign in not only in concept and lexicon but also to American tongue and palate. However, an increasing numbers of American gourmets have generated popular interests in this concept, and food production in general (Tubek, 2008). Vidalia Onions are a product that, since its first appearance in a southern Georgia farmers market in the 1930s, has generated premium profits based on its distinctive, reliable sweetness. The low level of sulfur in the soil in the official growing region, coupled with the right mix of sand and weather, comprise the terroir in Vidalia. Terroir is only implied and assumed, rarely used to describe the Georgia onion by producers or experts (Severson 2014).

The post-harvest technology that this research is based around provides means for noninvasive detection of internal defects and diseases. Because of the physiology and harvesting practices of modern onion production, onions are susceptible to these types of bacteria and fungi. Normally these defects are assessed by skilled human labor. Nonetheless, humans are not as reliable as machinery. Many factors affect the quality of inspections, including availability of experienced workers, insecurity from changes in immigration policy and enforcement, working conditions, and the unobservability of disease and defect (Boyhan and Torrance, 2002).

The amount of disease varies by weather events, harvesting practices, storage, storage techniques, and handling. Sorting, sizing, and culling take place a various stages in the packing process depending on the firm which implies that this would be the same for any new post-harvest technologies. Increase in mechanical harvesting and decrease in the proper use of $\mathrm{CO} 2$ storage continues will begin to change the concerns about diseases, both of which may increase internal rot and latent damages undetectable upon visual inspection(Torrance, 2011). 


\section{The Terroir in Vidalia}

The primary justification for terroir in Vidalia Onions is a result of its geographic boundaries. Vidalia Onions are a sweet onion are afforded their differentiating name by the state if they meet the geographic requirement being within the 20 counties in southeastern Georgia and are an approved variety grown by a registered producer. The restrictions on the production area imply terroir, thought they were drawn using political boundaries and justifications (Bryan 1987; Torrance 2011).

There are multiple elements that contribute to creating such a distinctive onion. The local soils are the primary ecological input that is often cited for the unique product. The soils of this area a very low in sulfur, an element that is proven to enhance sweet onions (Lee, 2009). Additionally, this region typically has high amounts of rainfall and irrigation that contributes to leaching the soil of this nutrient (Yoo, 2006; 2012).

The type and variety of onion also contributes to producing a sweet onion (Yoo, 2006). Spanish style, granex hybrid, yellow onions are traditionally the only onions that can be grown as a Vidalia Onion. Japanese varieties are being added to the list though significantly lacking the consistency and level of sweetness of others (Torrance, 2011). The purpose of these varieties is to provide earlier harvests (Torrance, 2011). The varieties that can be used are annually approved by the State government. The state as well as private industry develops these varieties.

Part of this struggle to achieve distinctly sweet onions compared to competitors from Texas, New York, and Peru is sweetness, a flavor, is not well understood (AAAS Annual Meeting, 2011; UGA Producers Meeting, 2010). Sugar content, lack of pungency, presences of sweetness, and combinations of chemical compounds have all been claimed as potential sourcesfor experienced onion sweetness. However, the Vidalia Onion industry is not the only group of sweet onion growers that are seeking to improve their seed stock and therefore end product, though they may be the only one with a certified and brand-controlledproduct. The spring supply of sweet onions begins with product from Central and South America, then Texas farmers ship their crop, and Vidalia onions come into the market.

Labor is an issue across Georgia and other southeastern states in the spring, but Vidalia growers do not expect problems finding workers to harvest a premium crop."We don't anticipate having any issues with our labor because we participate in the guest worker program," Mr. Pazderski said. "As long as we don't have any snags getting the guest workers to the U.S., we'll be just fine. We've not had any issues to date and have done everything that we normally do in preparation for Vidalia season."2

The state and federal legislation that protects the Vidalia identity is premised on its terroir or the specific ecology of the product. None of the legislation protects the ecology of the space that is construed as foundational to the quality of the product. The certification of sweetness of this product is determined through variety trials and taste tests that shape the lines selected for propagation. Not only are the variety trials, which directly affect the signature quality of the Vidalia Onions not being conducted to enhance this quality but additional public research for this industry assumes the quality of terroir as well.

The post-harvest technologies being developed are meant to detect internal diseases some time before they reach the consumer. The role of this product is unclear because it is unclear of its place in the packing line as well as its feasibility as a commercial tool since all types of this postharvest are at early development stages (Torrance, 2011). Either way, however, the benefits are targeted at the producer quality not consumer quality. Producer quality focuses at the characteristics of the product that allow for more agreeable product in the supply channel. These post-harvest technologies specifically target shelf life (Shewfelt 1993; Torrance 2011) which is not as aspect of terroir. The argument could be made that this technology could be a unique human input of Vidalia onions but alas, this technology is also being primed for adoption in other sweet onions across the nation. Vidalia sweet onions to generate higher prices than other sweet onions, and providing a guarantee to consumers of less rot can strengthen the justification for this price. Although not an element of terroir, the research and extension efforts supporting product quality serve to eliminate issues that might detract from the taste, flavor, and texture that are dimensions of terroir for the Vidalia onion. Being able to meet the expectations of consumers in critical in promoting a brand of product. Brand is a way of communicating to a consumer the elements and characteristics of a product.

2 http://www.theproducenews.com/index.php/category-list/9-story-cat/7231-great-weather-has-vidalia-onions-heading-forearly-start 
And while terroir can be identified as a type of branding is not necessarily terroir. The natural or human ecology of the Vidalia region does not create rot-free or rot reduced onions therefore, these developing post-harvest technologies do not protect its terroir.

\section{Terroir as a Food way}

Food ways are the cultural, social and economic practices relating to the production and consumption of food, largely involving the culinary practices of a region (Brown and Mussell 1984). As terroir is a distinctively French coined term, it should be expected that terroir in America follow its model in terms of its social meaning; terroir in other nations is a food-way as well as a production way yet the terroir of Vidalia onions is only the latter. The appellations de origin controlle in France at the turn of the 20th century were a result of the champagne producers seeking protection of the name of their product (Trubek, 2008). It was, simply a marketing scheme, to protect the product reputation and therefore its prices. With this, the producers guarantee consistency but distinctiveness of their product.

The French government supports not only this as a marketing scheme by providing legal protections to the name of the product but also to the consumers by insuring that producers uphold their promise of quality distinctions (Trubek, 2008; Paxson, 2010). Other than the geographic boundaries the onion varieties, which are limited in their ecological and therefore terroir foundations, the producers of Vidalia onions have no promise to uphold on providing the unique qualities that were the justification for their protection. The French government has, over a period of decades, insured the food-ways of terroir; the knowledge and appreciation of local foods and food customs has become culturally embedded for the French people. The government began producing literature and reviews on local and folk foods as a means to promote nationalism and domestic tourism (Turbek, 2008). These materials not only created awareness as a marketing scheme would but also generated the valuation of local foods defining their cultural uses and roles. This appreciation of the history and customs of Vidalia onion is not promoted in the United States. This claim to sweetness is a marketing tool that recognizes a distinctive regional food item, a production of Terroir, as it has been since the promotion of Vidalia Onions on the highway vegetable stands in the 1930s.

\section{Method}

Research for this project was conducted centrally in the 20 counties of the Vidalia Onion production region in southern Georgia. We attended several field days, vegetable conferences, and visited several onion packing facilities in advance of the focused group interviews. During these visits we engaged in a wide range of discussions with topical experts, producers, researchers, extension personnel, and grocery managers. The venues for the focused group interview meetings were three restaurants selected for the convenience of the respondents. These guided conversations with Vidalia onion producers addressed topics related to technological change and its impact on the onion industry. The meetings explored perceptions of post-harvest technologies and their integration into farm operations as influenced by such factors as economic investments or consumer expectations (Rossi et al., 1983).

We relied on extension lists of individuals in the 20 county Vidalia regions who are qualified to discuss Vidalia onion production and post-harvest technologies. We included relevant experts other stakeholders who volunteered or other followed their interests to participate in the group meetings (Rossi et al., 1983; Schonlau et al., 2002). The respondents all had direct and broad involvement in Vidalia onion production processes. Their insights may help ensure that the relevant technologies are being developed to address the needs and capacities of producers.

Participants were asked to assess technology needs, identify alternative technology options, and prioritize technology issues in the industry. Each group interview had technical change through advances in sorting technology as a fundamental theme. We did not employ recordings of the conversations, instead relying on detailed notes take by the researchers. The first meeting in the community will be referred to as Alium and involved14 participants. Lakeside, the second community included nine farmers and packers, and Bellville, the last venue, eight farmers, packers, and extension personnel. The small number of producers and limited geographic area in the Vidalia onion terroir can make identifying individuals possible, so many of the attributions were slightly altered to ensure confidentiality. A moderately priced meal was the only compensation for group interview participants. 


\section{Results}

\section{Alium Community}

The Vidalia industry is a broad mix of famers who only grow onions, some who grow onions and have their own packing lines, and a small number of larger operators who purchase or contract for onions from farmers, grow their own onions, and in some cases have contract relationships with operations in Peru and Mexico to import sweet onions for packing when the Vidalia crop has been exhausted. Large operations have large and sophisticated packing lines; small packers often have old, but simple and understood technology that is readily repaired with commonly available parts.

An emerging technology mechanized with conveyor belts using X-ray scanning and interpretation could help farmers investigate the onion's internal defects and help grading the onions based on their sizes, degree of sweetness and quality. The capital investment required to install advanced technologies was a touchstone for producers at all three venues.

Eight farmers and two county agents attended the Allium session. All of them are male. There are not many women onion growers in the Vidalia terroir, but one woman the county agent and farmers mentioned is an organic Vidalia grower, utilizing a greenhouse in her production, but it was reported that she was too busy to join the discussion. The discussion touched on a broad range of issues about onion production, labor, marketing, contracts, prices and quality.

Production. Farmers in the session owned medium to large onion farms. They produce Vidalia on land ranging between 200 to 1,500 acres.

Marketing/Contracts. Variety is always the key to attract consumers. Mal, a farmer from Stone County stated that "Consumers pay more attention to the sizes." Different sizes have different prices, "Last year I had five different types of onions to satisfy the customers."

Most of the farmers sell their onions to Kroger and Wal-Mart and they usually have contract with them. Some of them mentioned that their onions got rejected from Kroger because of his onions did not meet size requirements. One of the functions of the sorting process is not only to determine defects but to allocate onions of similar size to various points on the packing line. Some buyers have very narrow specifications on the size and color of onion that they will accept for their retail units.

Price. The Vidalia onion has price premium because it costs more to produce. Because of the high market profit margin, farmers have opportunity to play with their prices when negotiating with large grocery stores, like WalMart and Kroger. But the condition is that they could meet the requirements that Wal-Mart or Kroger put forward.

Technology. Every new technology is not perfect. Some farmers concerned the effectiveness of the machine to diagnose onions' internal defects. Some were concerned the speed of the sorting machinery. Mal, a farmer from Stone County asked "How many onions can be processed in one hour? ...I am worried it is too fast to pick out the bad onions."

Aries, a young farmer with two kids, 3 years old and 4 months old, concerned that "What if the high-tech machine does not work?"

The county agent Rex questioned "How does the machine rate the flavors?" He pointed out that farmers are more likely to apply the technology to detect the internal defects instead of flavors. He suspected that the machine's grading on flavor is not reliable because everybody has different tasting to sweetness.

He also stated that "What we need is not a 5 million dollars' worth machine, what we need is some technology really can help us detect the defects."

Labor. Growers are losing labors to work for them recent years. Jing, a farmer who just took a vacation with his family from New York City mentioned that "Since the first week of July last year, 15\% percent of workers on my farm were gone because of fear." It either could be due to the border war or improper paperwork. Growers also concerned about the labors' productivity, whether they can pick out the bad onions from the conveyor belt quick enough to avoid packing them in good baskets.

Adoption. Famers are rational. They usually apply cost and benefit analysis to make decisions. The price of the investigation machine is not settled yet, but it is estimated not a small number. Farmers concerned the price of the high-tech machine and need to calculate how long they could get their money back. 
Aeries mentioned "if right now (quality) is big issue, I would buy the machine. But I need see my money back. Then years after, if quality is no longer a problem, I may change my opinion." "If Kroger can pay me \$2 more per box of onion, maybe it is reasonable to buy the machine." At last, the mentor asked "If there some improvements the technology can do, what are your suggestions?"Farmers hoped the machine can be effective to pick out the rotten onions. Mal mentioned again "If the onions pass by on the belt, whether it can pick out the bad ones is still a concern. I hope it can be slowed down."

\section{Lakeside Community}

The Vidalia onion produced in in the following counties in Southeast Georgia: Appling, Bacon, Jeff Davis, Montgomery, Tattnall, Telfair, Toombs, Treutlen and Wheeler, as well as portions of Dodge, Jenkins, Laurens, Long, Pierce, Screven and Wayne. Approximately 225 growers cultivate Vidalia Onions on over 14,000 acres. About 125 handlers are involved in the grading, packing and distribution of Vidalias.

Planting. Rex told us "Every year the planting strategy is different due to different weather. The rain is late this year and it is dry in Georgia."Besides onions, farmers also produce corns, peanuts, cottons and wheat.

Production. As asking how to fix their machines on farm, Keith told us they use technicians to tell them whether it works for them. Cliff told us "We also get information from technician about maintenance and troubleshooting problem. We can replace a bad machine within 3 hours."As for the question "How to deal with the bad onions", Keith said "we chop it and give them to cows." Young said "To cows and some food processor also use them."

Marketing. Farmer told us "If there are \$2 premium on jumbo, we will produce jumbo. Otherwise, we will do mediums." "If customers come to say I want more mediums, two weeks after, you shape it." Famers can control the onion sizes by controlling the production distance between onions. If onions are planted near, they compete for nutrition and only small ones could be produced.

Adoption. The diseases caused rotten inside cannot be picked out by traditional sorting technology. Selling bad onions may ruin farmers' reputation, owning an X-ray machine is not only good for farmers, but also beneficial for insurance company because the grading machine could tell the good onions from the bad ones and help save them.

Benefit and cost analysis takes a role in farmers' decision making. Keith mentioned "Several hundreds of acres you have could worth to have the machine."Rex also mentioned that "not everyone is co-op; it is not feasible for everyone to buy the machine." The X-ray based grading machine exists in Norway. But Rex pointed out that we have different environment, sorting, and handling method to Norway agriculture, he concerned the feasibility of employing the machine for Vidalia farmers. Young said it is more sensitive if costumers want high-quality onions. Keith said "I don't know how fast the machine is. If it scans 100 onions per second, that would be too fast. I don't know whether it is precise enough." The mentor asked "if the machine can do sorting in the field before harvesting it, is it helpful?" Keith said "We cannot think we have patience to do it, because we have so many onions in the field." Keith stated that "Efficiency is the bottom line. Marketing may works or not works, it cannot be controlled. If the machine can save us money it works."

Labor. Keith stated that the machine could replace more people on the sorting line, "I can cut down handling to let them move boxes. It could save 12-15 labors, giving them the minimum wage."

\section{Bellville Community}

The third session was held at a barbecue restaurant in the county seat of a Vidalia county of nearly 2,500 people. Along the country road to Bellville, we see a lot of onion packing houses. Three farmers came to the session. Darren and Darren Jr., father and son, operate their farm 4 to 5 months per year and operate under old-fashion techniques. They depend less on high-tech machineries in their production. Spencer, works on one of the largest farms in the area that packs and ships onions year round. All of them shared their opinions about X-ray grading machine with us.

Marketing. Darren told us they do not sell their products directly to consumers either through farmers' market or CSAs or online booking systems because they do not have time to meet consumers. They have tight relationship with brokers and usually sell their products to Winn Dixie. Farmers need to adjust their production to meet grocery stores' requirements because they usually need particular size in particular weeks. 
Price. The Vidalia onion has its premiums due to its good tasting. But other varieties of onions are usually competitors to Vidalia onion. Rex told us onions from Mexico sell for \$6 per bag (20 lbs.) compared to Vidalia onion with $\$ 16$ per bag.

Sorting. Spencer told us that on the Blend farm, they can sort onions based on sizes or weight or size/weight combination, but the technology which could inspect the internal quality is not available.

Technology Adoption. The X-ray grading machine exists in Norway, and one extension agent told us he once observed X-ray based machine in Vermont, U.S. They can scan density and internal quality of vegetables.

Agent Rex questioned the application possibility of the machine "I am afraid we don't have tight (onion) skin here, it is different from Norway."

Spencer from the large farm is more likely to depend on university research and extension. He questioned "Whether UGA can validate this X-ray technology, is it good or bad for farmers?"It is estimated from the X-ray machine company that the four line X-ray grading machine is about 2 million dollars, but final price is not settled yet. It is hypothesized that money can be paid back within 3 to 5 years for farms on average.

Spencer pointed out that "No matter two line or four line machine, you must have money."

Cliff said "Everybody thinks technology is good. The question is if the company can ensure $100 \%$ check, that is a good selling point. And if they can estimate a cost of 2 lines, 4 line or even 8 line's cost respectively and can document what the machine can and cannot do. That would be a help." He also said "Two lines might be feasible for small farmers."

The mentor asked "Whether you expect buyers to require farmers to use the machines." Famers did not think so. But Spencer said "Producers may tell consumers it is scanned by the X-ray machine, it is quality guaranteed. Then the buyers may say "Ok, we buy it from you." It is possibly a marketing strategy to sell good quality onions. Darren worried about "If the machine breaks down, what I can do. It must work as a full-time staff, or it won't work out." He also concerned "How much money need to fix the machine if it breaks down?" He also told us if machines break down on their farm, they just go to equipment stores (such as South Georgia equipment) to buy the components, there is no technician to help them on farm. They also asked "whether the machine can be washed", "I would like to see how it runs."

Rex reminded the farmers that "The grading machine really can help you especially in bad years. If the crops are rotten in the field, you may not throw them all. If you can grade them, maybe $20 \%$ of good onions can be saved."

Labor. Darren told us on average there are 35 packers in one packing house. The grading machine may save them a lot labors. Spencer said "On my farm, just electronic sizing power could save us 30 to 40 percentage of labor."

\section{Conclusions}

The results from this study show how technical change challenges the boundaries of terroir and grower tradition. New ways of scanning and storing onion create new possibilities and investment requirements for growers Increased in-depth interactions between investigators and stakeholders can ensure that the new technologies put into practice. Growers who elect to delay or avoid new storage and production approaches face risks that may put them at a competitive disadvantage from higher storage losses. Storage research augments the commercialization ofsorting and storage technology for sweet onions like Vidalias. These approaches already extend to other fruits and vegetables. The defining factors of the Vidalia onion including geographic bounds, original production orientation, and governmental involvement emulate the geographic indications enforced in Europe. But in the context of this research, fueling this sociological examination of Vidalia Onions, the absence of the spirit of terroir becomes apparent. Post-harvest technology such as x-ray, infrared/spectrometry, and microwave scanning for internal defects and disease supports brands, not terroir. These technologies and research activities do not protect the unique character of these onions, nor do they result in distinct production practices as another element of its terroir. Additionally, there is an absence of consumer cultural valuation that other terroir products have. Post-harvest technology such as x-ray, infrared/spectrometry, and microwave scanning for internal defects and disease supports brands, not terroir. These technologies and research activities do not protect the unique character of these onions, nor do they result in distinct production practices as another element of its terroir. Additionally, there is an absence of consumer cultural valuation that other terroir products have. Producers are generally view the advent of advance internal onion scanning techniques as advantageous to them and the industry. 
Producers who pack onions are cautiously optimistic about the prospect of improved detection on internal defects but are concerned about the capital costs of new equipment. Large-scale food systems that contract for and purchase large volumes of onions may require the use of advanced onion scanning technologies, creating the prospects for industry shakeouts and increased concentration of distribution.

\section{References}

AAAS Annual Conference. 2011. Proceedings Notes. Washington, D.C.

Boyhan, G.E. and Torrance, R.I. 2002. Vidalia Onions - Sweet Onion Production in Southeastern Georgia. Hortechnology. 12(2). 694-706.

Brown, Linda Keller and Kay Mussell. 1984.Ethnic and Regional Foodways in the United States : the Performance of Group Identity. Knoxville : University of Tennessee Press.

Georgiev, A.S. L.F. Kostadinova, R. Gabrova, N. Shopov. 2010. Increasing the rate of operation of automatic quality classifiers for agricultural products - software and hardware decisions. ISHS Acta Horticulturae 858: III International Conference Postharvest Unlimited 2008

Glenn, Jolene J. 2011. A discussion on the presence of terroir in the SCRI Onion Research. Unpublished Manuscript. Auburn Alabama: Department of Agricultural Economics and Rural Sociology, Auburn University.

Lee, E.J., et al. 2009. Application of Extra sulfur to high-sulfur soils does not increase pungency and related compounds in shortday onions. Scientia Horticulturae.123. 178-183.

Lee, E.J., et al. 2009. Application of Extra sulfur to high-sulfur soils does not increase pungency and related compounds in short day onions. Scientia Horticulturae.123. 178-183.

Lembe S. Magwaza, Umezuruike Linus Opara, Hélène Nieuwoudt, Paul J. R. Cronje, Wouter Saeys and Bart Nicolaï. 2011. NIR Spectroscopy Applications for Internal and External Quality Analysis of Citrus Fruit-A Review. Food and Bioprocess Technology. Volume 5, Number 2, 425-444, DOI: 10.1007/s11947-011-0697-1

Li, C., R. Gitaitis, B. Tollner, P. Sumner, D. MacLean. 2009. Onion sour skin detection using a gas sensor array and support vector machine. Sensing. \& Instrumentation for Food Quality and Safety 3: 193. doi:10.1007/s11694-009-9085-1

Maria Rosario P. Mosqueda. 2010. Predicting the economics of X-ray inspection technology in sweet onion packinghouses using simulation modelling.Biosystems Engineering 105 (1): 139-147.

Paxson, H. 2010. Locating Value in Artisan Cheese: Reverse Engineering Terroir for New-World Landscapes. American Anthropologist 112, (3) 444-457.

Severson, K. 2014. Vidalia onions: a crop with an image to uphold. New York Times April 7, 2014https://www.nytimes.com/2014/04/09/dining/vidalia-onions-a-crop-with-an-image-to-uphold.html

Shewfelt, R.L. 1993. Measuring Quality and Maturity. 99-124 in Postharvest Handling: A Systems Approach, edited by Taylor, S. San Diego, CA.

Slocum, Walter L. 1962. Agricultural Sociology: A Study of Sociological Aspects of American Farm Life. New York: Harper.

Torrance, R.I. 2011. Personal Phone Interview.

Trubek, Amy B. 2008. The Taste of Place: A Cultural Journey into Terroir. Berkeley, University of California.

UGA Production Meeting. 2010. Proceedings Notes. Glennville, Georgia.

Yoo K.S., Lee E.J., Patil B.S. 2012. Changes in flavor precursors, pungency, and sugar content in short-day onion bulbs during 5-month storage at various temperatures or in controlled atmosphere. Journal of Food Science, 77: 216-221

Yoo, K.S., 2006. Differences in onion pungency due to cultivars, growth environment, and bulbsizes. Scientia Horticulturae. 110. 144-149. 